\title{
Atendimento psicológico em instituições: da tradição à fenomenologia existencial
}

\section{Psychological care in institutions: from tradition to existential phenomenology}

Juliana Vendruscolo*

Universidade de Ribeirão Preto - UNAERP, Ribeirão Preto, São Paulo, Brasil

\begin{abstract}
RESUMO
A delimitação do lugar da Psicologia como ciência continua sendo trilhada na atualidade, gerando embates relativos à classificação. Um importante campo de discussão foi aberto com a inserção do psicólogo em novos espaços de atuação. Como deve ser a intervenção no contexto institucional? Diferentes técnicas de atendimento psicológico foram desenvolvidas. O objetivo desse trabalho é apresentar nomenclaturas que diferenciem algumas modalidades de atendimento psicológico, utilizadas em instituições, e, posteriormente, desconstruir tal concepção presente na tradição da psicologia científica. Abre-se espaço para compreensão fenomenológico-existencial do atendimento do psicólogo institucional. Nesse artigo um caso foi relatado e discutido a partir da questão norteadora (não formulada aos participantes) "Como se dá a relação terapêutica?" Conclui-se que a relação terapêutica, no âmbito clínico ou institucional pode ser concebida apenas pela pré-ocupação por anteposição libertadora. Não há necessidade de classificações e diferenciações técnicas para especificar as modalidades de atendimento psicológico possíveis no cenário contemporâneo.
\end{abstract}

Palavras-chave: Psicologia Institucional, Psicologia da Saúde, Psicologia Fenomenológico-Existencial.

\section{ABSTRACT \\ The delimitation of the place of Psychology as a science is still being}

drawn in the present days, generating discussions relatively to classification. An important field of discussion was opened with the insertion of the Psychologist in new operating spaces. How should thePsychologist intervention be in the institutional context? Different psychological care techniques have been developed. The objective of this work is to present nomenclatures that distinguish some psychological care modalities, used in institutions, and, eventually, deconstruct such conception, present in the scientific psychology. A space is being opened for an existential phenomenological understanding of the institutional psychologist care. In this study, a case was reported and discussed, departing from the guiding question (not exposed to the participants) "How does the therapeutic relation happens?" We get to the conclusion that the therapeutic relation, in the clinical or institutional scope can be conceived only by the preoccupation with a liberating preplacing. There is no need of classifications, 
nor technical differentiations to specify the possible modalities of psychological care in the contemporary scenario.

Keywords: Institutional Psychology, Health Psychology, ExistentialPhenomenological Psychology.

\section{Práticas Psicológicas em Psicologia da Saúde: uma demanda de técnica}

A Psicologia traz em sua história, um percurso de embates gerados em torno da necessidade de sua classificação. Por certo período esteve associada à Filosofia, porém, com a crescente valorização do pensamento científico-natural, começou a surgir o interesse de inseri-la no grupo de tais ciências. Giorgi (1985) descreve esse momento histórico marcado pela fundação do primeiro laboratório de Psicologia Experimental, de Wundt, na Alemanha, mas evidencia, que já havia autores preocupados em apresentar a Psicologia como Ciência Humana. Dentre eles, Brentano e Dilthey. Esse caminho, que procura delimitar o lugar da Psicologia como ciência, continua sendo trilhado na atualidade, concomitantemente às delimitações da Psicologia em diferentes áreas de atuação.

Em 1960, a profissão do Psicólogo foi regulamentada (SPINK, 2003), mas é interessante notar que já havia a atividade do psicólogo no âmbito hospitalar. Encontramos nesse período o cerne do que hoje conhecemos como Psicologia da Saúde.

Mesmo com os entraves teóricos, a "área da saúde", termo comumente utilizado para designar a atuação relativa à Psicologia da Saúde, tem sido foco de constantes estudos, bem como tem se constituído como terreno fértil para contratação de psicólogos. Até meados da década de 90, a Psicologia Hospitalar era a representação mais evidente da área da saúde. Nesse período, surgem publicações nessa temática, assim como congressos e encontros relativos ao trabalho na instituição hospitalar (ANGERAMI, 2006). Alguns setores específicos ganham destaque nas pesquisas realizadas, sendo a Psiconcologia um desses expoentes. A literatura, gradativamente, começa a anunciar uma ampliação: a Psicologia Hospitalar, até então nome de disciplinas, congressos e livros, passa a integrar a grande área da Psicologia da Saúde.

Vale ressaltar que há 20 anos surgiu a proposta de democratização da saúde com o SUS - Sistema único de Saúde. Segundo Paim (2009), muitas conquistas podem ser comemoradas em relação à concepção, nascimento e implementação do SUS, mas os obstáculos também se destacam. De acordo com Carvalho (2009) a saúde mental, que constitucionalmente integra a saúde, deveria ser respeitada. Portanto, pensar na Psicologia da Saúde envolve os diferentes níveis de atenção à saúde, em seus respectivos locais de 
atuação: primário (Unidades Básicas de Saúde-UBS e Unidades Básicas Distritais de Saúde - UBDS); secundário (Unidades de internação) e terciário (cuidados relativos à reabilitação). A presença do psicólogo tem sido cada dia mais valorizada e exigida nos diferentes espaços de atenção à saúde (MINAYIO; CAMPOS; AKERMAN, 2006). Vale ressaltar que a Psicologia está inserida tanto a partir de uma proposta mais relacionada aos aspectos sociais, quanto mais direcionadas às questões pertinentes aos atendimentos clínicos institucionais, individuais ou em grupo, que constituem o foco desse estudo.

Os profissionais da psicologia têm enfrentado muitas demandas ao se inserirem no setor da saúde, seja no espaço público ou privado. A expectativa em relação ao trabalho no campo da saúde mental vem, na maior parte das vezes, marcada pela concepção mecanicista e biomédica do processo saúde e doença. De acordo com Organização Mundial da Saúde, a saúde pode ser considerada como um estado de bem-estar físico, psíquico, social e espiritual total, sendo assim, se esse estado for interrompido por algum fator ele deverá ser restaurado o mais rápido possível (VALLE; FRANÇOSO, 1997). Quando um pedido de avaliação ou de atendimento psicológico é realizado, ele vem acompanhado de uma expectativa do solicitante, que na maior parte das vezes é algum outro profissional da saúde, de resolução de algum conflito, bem como de minimização do sofrimento que o indivíduo adoecido está vivenciando.

Sendo assim, um importante campo de discussão começou a ser aberto a partir da inserção do psicólogo nesses novos espaços de atuação. Como deve ser a sua intervenção no contexto institucional na área da saúde? Há necessidade de se empregar técnicas específicas para diferentes momentos? Deve ser respaldada pelo modelo clínico, representado prioritariamente pela psicoterapia? Quem solicita o atendimento necessariamente é o cliente/paciente, ou seja, é aquele cuja demanda será atendida? A literatura apresenta um grande número de pesquisas que estão de alguma forma, relacionadas a esses questionamentos. Alguns autores serão citados a seguir para ilustrar essa afirmação.

Sebastiani e Maia (2005) apontam a necessidade do psicólogo se instrumentalizar, com técnicas específicas para atuar com o paciente que passará por um processo cirúrgico, o que se inicia através do conhecimento de alguns processos de respostas previstas na experiência desse paciente.

Gorayeb (2010) salienta a necessidade de esclarecer que a Psicologia da Saúde não é a mera aplicação da Psicologia Clínica na área da Saúde, mas configura-se como uma área específica, que requer técnicas e métodos específicos. Para esse autor, em sua experiência na área, os conhecimentos científicos, pautados na Psicologia Experimental são essenciais. 
A Interconsulta Psicológica é apresentada por Santos et al (2011), como instrumento metodológico utilizado pelo profissional de saúde mental para compreender e prestar assistência ao paciente em hospital geral. Em seu estudo, as autoras apresentam resultados que apontam a solicitação de tal modalidade, prioritariamente por médicos e enfermeiros, tendo como motivos do pedido os sintomas psicológicos relacionados ao adoecimento e a identificação do comprometimento da adaptação do paciente à hospitalização.

Esses e outros trabalhos contribuem inegavelmente com a prática psicológica na área da saúde. É possível afirmar que se destinam a sistematização de uma prática, que nascida no modelo biomédico, desenvolveu-se rumo à conceituação biopsicossocial do atendimento em Psicologia da Saúde. Entretanto, tomando a Psicologia a partir da proposta fenomenológico-existencial, e, portanto, desprendendo-se de qualquer proposta de manejo do aparelho psíquico (FEIJOO, 2011), surge a necessidade de buscar outra forma de compreender e fazer Psicologia da Saúde. Sendo assim, partiremos da apresentação de algumas técnicas de atendimento psicológico relacionadas ao contexto institucional, para, em seguida, ao desconstruirmos essa noção de psicologia aplicada, apresentarmos a atuação com base fenomenológico-existencial como norteador da prática na área da saúde.

\section{Sobre as técnicas - da atitude natural}

Em estudos anteriores (VENDRUSCOLO, 2005; VENDRUSCOLO; BARRETO; EI KHOURI; FERREIRA; MEZZIARA, 2008; VENDRUSCOLO; DEL LAMA, 2008; VENDRUSCOLO; COSENZO; FESTUCCI; SOUZA, 2008; VENDRUSCOLO; COSENZO; FESTUCCI; SOUZA, 2008;) é possível encontrar dados significativos quanto à pertinência de diferentes modalidades no atendimento institucional de clinica-escola de psicologia e serviços a ela relacionados. Esses estudos foram embasados pela metodologia fenomenológica em psicologia, porém, mesmo com apoio nessa literatura, ainda é possível notar a atitude natural. Acrescentar à expressão Atendimento Psicológico um complemento para designar o contexto em que ele é realizado (em hospital, em oncologia, em luto, dentre outros), caracteriza uma fragmentação do existir humano em diferentes situações. Esse aspecto se dá em uma concepção de prática psicológica pautada no pensamento científico-natural, em que as diferentes modalidades são concebidas como organizações e técnicas que visam atingir o modo mais adequado de realização em cada contexto. Segundo Sá (2009)

Mas, mesmo quando a experiência é tomada como objeto privilegiado de análise, trata-se, em geral, da experiência 
enquanto vivência psíquica e, portanto, encontramo-nos ainda em uma atitude natural, que considera a experiência a partir de uma realidade em si de processos psicológicos transcendentes à própria experiência.

Podemos destacar algumas delas a seguir.

\subsection{O Plantão Psicológico}

O Plantão Psicológico pode ser compreendido como uma proposta inovadora que segundo Mahfoud (1987) constitui um desafio a ser vivenciado. Seria um "aprender da experiência a partir de um empenho com a realidade assim como ela é para de dentro de outra transformá-la" (MAHFOUD, 1999, p.11).

\subsection{O Aconselhamento Terapêutico - Proposta de Forghieri (2007)}

O Aconselhamento Terapêutico é uma prática que está associada à psiquiatria, mas também ligado aos movimentos de Orientação Profissional e vocacional que surgiram a partir de 1900, nos Estados Unidos e na Europa. Essa prática se expande e chega até a clínica psicológica.

\subsection{A Psicoterapia Breve}

A literatura aponta com muita clareza a base psicanalítica presente no surgimento da Psicoterapia Breve (BRAIER, 1997). Lemgruber (1997) descreve a origem dos termos breve ou curto prazo calcados na tentativa de Ferenczi, discípulo de Freud, em encurtar o tempo e de duração dos tratamentos psicanalíticos. Sendo assim, a proposta dessa psicoterapia teria apenas o diferencial do tempo de duração reduzido, pois o ponto de vista psicodinâmico na compreensão do problema do paciente seria mantido. Trata-se, portanto, de uma técnica que, oriunda da psicanálise freudiana, foi se desenvolvendo e constituindo alguns conceitos básicos como: Experiência Emocional Corretiva; Aliança Terapêutica, Foco e Atividade e Planejamento.

De acordo com Fiorini (2004) a Psicoterapia Breve é um processo terapêutico realizado dentro de um tempo limitado para atender e se adaptar às condições e demandas institucionais. Suas raízes psicanalíticas remontam o período de Guerra, uma fase de grande demanda.

Segundo Vendruscolo (2009) a Psicoterapia Breve, compreendida a partir de uma abordagem fenomenológico existencial, se constitui em um espaço de tematização do próprio existir, ou seja, acerca das possibilidades existenciais e da reflexão sobre a experiência vivida. 


\section{Sobre o atendimento psicológico - da atitude fenomenológica}

Diversos e distintos conteúdos estão presentes no discurso do paciente. Muitas vezes encontramos comportamentos similares como reação a um adoecimento, bem como manifestações de sentimentos muito próximos frente à constatação de uma perda. Essas experiências ocorrem no cotidiano das pessoas, que de início e na maior parte das vezes, encontra-se diluída no impessoal. Segundo Sá (2008) a prática clínica da Psicologia parte da mudança da atitude natural para a atitude fenomenológica. Para o autor, na atitude fenomenológica, independente de como pode ser denominada a modalidade do atendimento, este se caracteriza como espaço de explicitação da experiência existencial.

O setting terapêutico, ou seja, o espaço físico, as condições ambientais de silêncio e não interrupção dentre outros aspectos, devem ser considerados e manejados da maneira que for possível na situação. $O$ que se tem é o indivíduo que está sofrendo, vivenciando um período de fechamento de suas possibilidades existenciais (FEIJOO, 2000). A relação terapêutica se constitui então como a abertura às possibilidades e o resgate do modo de ser temporal e livre e não necessariamente a mudança de comportamento ou a eliminação do sintoma. Esta relação se dá em liberdade e não é uma técnica que se aplica, ou uma ferramenta. Ela visa facilitar ao cliente falar a si mesmo, de uma forma própria e dessa forma o homem assume a responsabilidade por suas escolhas. Além disso, se percebe lançado no mundo, entregue ao seu poder-ser mais próprio (VENDRUSCOLO, 2009).

\section{Caminho metodológico}

Esse trabalho integra um projeto de pesquisa do Serviço de Atendimento Psicológico Fenomenológico-Existencial da clínica-escola / UNAERP e demais serviços a ela relacionados. Os dados apresentados nesse estudo são relativos ao ano letivo de 2010, em atividades realizadas sob supervisão de um docente, contando com a participação de estagiários da $9^{a}$ etapa do curso de graduação em Psicologia.

O projeto de pesquisa foi realizado em três locais distintos: O serviçoEscola da universidade, o Hospital Universitário e um Hospital beneficente da cidade.

Participaram deste estudo os clientes (crianças, adultos e adolescentes) que foram submetidos a alguma das modalidades de atendimento psicológico referidas anteriormente em algum dos locais de atendimento. Porém, nesse artigo apenas um caso será relatado. 
Será identificado de modo fictício como João, 23 anos.

Os dados foram obtidos a partir da ocorrência dos atendimentos psicológicos individuais ${ }^{1}$, que foram transcritos procurando manter 0 maior grau de fidedignidade possível e compreendidos a partir de uma questão norteadora que esteve implícita nessa pesquisa (e não foi formulada aos participantes) - "Como se dá a relação terapêutica?"

\section{Resultados e Discussão}

\subsection{Acolhendo João}

João, 23 anos, foi internado em um hospital público de nível secundário com episódios recorrentes de diarréia e perda de peso acentuada acompanhada de um quadro de desnutrição. Já possuía o diagnóstico de retocolite ulcerativa e estava sendo investigado um possível tumor pulmonar.

$\mathrm{Na}$ solicitação de atendimento psicológico feita pela equipe médica havia a descrição de um paciente depressivo, pouco colaborativo e "sem vontade de se ajudar". O texto também dizia: "Solicita-se avaliação e conduta pra ajustamento do paciente ao seu tratamento." É importante ressaltar que os pedidos de interconsulta psicológica em hospital geral normalmente já chegam até o psicólogo com um "diagnóstico" prévio dos distúrbios psíquicos, bem como com as indicações da conduta que deve ser tomada.

No primeiro atendimento, o paciente ao ser indagado como estava, disse estar tudo bem, que se encontrava internado há 15 dias e, quanto aos sintomas, disse que há dois anos apresenta este diagnóstico e que estava tomando remédio.

João se mostra, de início, à maneira do "tudo bem". Está na cama, se esvaindo em fezes e sangue, sem forças e diz estar bem. Como é isso para ele? Como é dizer tudo bem nessa situação? Qual o sentido dessa experiência para ele? Até aqui só temos interrogações e nenhuma resposta ou explicação. Qualquer tentativa de esclarecer tais questionamentos seria no mínimo como saltar na frente de João para dizer-lhe quem ele é.

Nesse momento, aproveitando a intervenção do enfermeiro junto ao paciente, um senhor se aproximou dizendo: "se vir aqui 20 pessoas e perguntar como ele está, ele irá dizer que está tudo bem, tudo bem até a bomba estourar."

Apesar de não sabermos por João sobre ele mesmo, ouvir os 
familiares nos permite apreender como ele é visto em sua família. Compartilhando esse momento da visita é possível sentir as relações acontecendo.

\begin{abstract}
Pergunto a esse senhor se ele era o acompanhante e qual o parentesco com o paciente. Ele me respondeu ser o padrasto do paciente e inicia o relato: "ele tem retocolite há dois anos, quando começou ele foi levado ao hospital de Itapetininga, onde ficou internado por dois dias, depois teve alta." Disse ser vendedor e que viaja muito, e quando chegou em casa e viu o João naquele estado, com diarréia e com sangramento, ele mesmo o levou a um médico particular e iniciou o tratamento com os medicamentos da rede pública, porque são medicamentos muito caros, e então o João se recuperou.
\end{abstract}

O atendimento psicológico institucional na área da saúde procura estar pautado na tríade: paciente, família e equipe. A equipe de saúde vê João, um garoto "pouco colaborativo" e deprimido, mas não sabem de onde vem, como é sua família, quem o visita, ou mesmo se não recebe visitas. É quase um intestino que tem um "dono" que não está agindo da maneira mais adequada à situação. O psicólogo, que vai até João, para que ele se mostre, acompanha o que se revela na situação.

Segundo o padrasto, como o João trabalhava, ele deixou para o mesmo o seu próprio tratamento. Ele deveria pagar a consulta com o médico particular a cada 3 ou 4 meses e seguir o tratamento. Mas João não deu continuidade ao tratamento e começou a comer de tudo, até pimenta (mostra-se indignado) e a beber. $O$ médico havia dito que ele poderia comer de tudo e aqueles alimentos que provocassem a diarréia deveriam ser eliminados, mas o João não seguiu nada disso e tomava o remédio por conta própria.

A responsabilidade é "passada" ao paciente, desde que siga o "correto". É evidente que há atitudes que podem prejudicar a saúde e outras que, ao contrário irão restaurá-la. Entretanto o psicólogo, nessa situação não precisa prender-se aos acontecimentos e muito menos às causas a eles relacionadas. Eles já estão aí, já ocorreram. São fatos. Resta desvelar, com João o sentido desse caminho, que certamente não se restringe ao adoecimento, mas ao modo de existir.

Este senhor também disse que não pode parar de trabalhar para ficar com o paciente no hospital e que sua esposa tem que cuidar das três filhas que estão em Itapetininga, que estão na escola. A avó e a tia, quando possível, iam visitar João, mas ninguém tinha como ficar com ele ali, e como João 
tem 23 anos, "está na hora dele se virar sozinho". Ele diz que fica irritado com o paciente, que ele não se cuida que tem 23 anos, mas não tem mentalidade dessa idade, que ele não para nem aqui e nem em Itapetininga, que come pimenta, e me pergunta: "ele pode comer pimenta?"

Qual é o tempo em que João está? Tanta gente dizendo o que ele deve fazer, como deve ser, qual é a dieta permitida, quais são as restrições. Podemos questionar: Quais são suas possibilidades? Quais restrições de sentido experiencia? É preciso não saber para compreender.

\begin{abstract}
Respondo que não sei, e que deve perguntar ao médio qual a dieta adequada para João. Aproveito esse momento para incluir João, e digo: "Tudo o que você quiser saber sobre sua alimentação, sobre o que você quiser saber sobre você ou quanto ao seu tratamento pode perguntar aos enfermeiros e eu estou aqui para poder ajudar você naquilo que eu puder e quando eu não puder, nós iremos ver quem poderá ajudá-lo." Sinto o paciente mais receptivo nesse momento e encerro o atendimento.
\end{abstract}

A conduta mais terapêutica nesse caso foi acreditar que João existia. No espaço terapêutico, que no hospital é estabelecido ao lado do leito, em pé, com gente passando o tempo todo, começa a surgir João como ser em abertura, com possibilidade de vir-a-ser. Um existente.

É preciso mudar o conceito saúde-doença. Associar saúde ao estado de bem-estar total é estático e ilusório; o ser humano é mutável, dinâmico, funciona com irregularidades e variações.

A doença surge como algo inesperado, fora do controle do sujeito, rompendo com seu caminho pessoal; gera sensação de vulnerabilidade, de medo, de perplexidade. Na psicologia da saúde é esperado que o atendimento psicoterapêutico controle sintomas e que dê segurança ao paciente com alguma enfermidade grave. Entretanto, o sujeito atribui um sentido à doença, de acordo com suas possibilidades e limites. Se a compreensão dos profissionais da saúde for ampla e integrada frente a qualquer adoecimento será possível transcender o aspecto técnico. Não há receitas, as atitudes devem ser caracterizadas por uma atenção à pessoa que adoece e não à doença em si.

Para Sá (2002) a técnica moderna tem como principais características controle e segurança. O autor continua e afirma:

A crítica Heideggeriana da ciência e da técnica não questiona a veracidade das mesmas e muito menos pretende substituílas por algum outro modo de saber ôntico mais verdadeiro. $O$ que a crítica pretende atingir é o modo histórico de relação que se estabeleceu entre homem e técnica na época 
moderna. O modo de desvelamento do sentido dos entes que a técnica possibilita não é mais nem menos verdadeiro do que aqueles possibilitados por outros modos de desvelamento de sentido, como a arte ou a religião. O problema com a técnica diz respeito à disposição de fascínio que ela impôs ao homem, fazendo com que o sentido dos entes, sua essência, se reduzisse exclusivamente ao aspecto que ela, técnica, desvela. (p. 20)

A idéia de que uma pessoa que adoece fisicamente deve, necessariamente, "superar" essa situação, ou seja, não se entristecer, ou nem mesmo sentir-se desanimada, está em perfeita consonância com a relação de fascínio que a técnica impõe ao homem. O psicólogo, atualmente integrante das equipes de saúde, é, na maior parte das vezes, convocado a usar suas técnicas para ajudar alguém. O problema é que ajudar, no cenário da psicologia moderna pressupõe a utilização de técnicas para adaptar, acalmar, ou seja, para que o especialista diga ao outro como ele deve se sentir e se comportar em relação à sua própria vida. Há um inegável desejo e senso de poder quase sempre travestido de ajuda.

É preciso disponibilidade para ouvir o paciente, integrando os sentidos que ele atribui à sua experiência; captar a experiência do outro como ela é vivida; possibilitar ao outro ser ele mesmo e assumir seus próprios caminhos; devolver a pessoa ao cuidado de si mesma.

Porém é preciso que o profissional também se perceba como existente e com realidade de dor, angústia, morte e impotência que a situação de adoecimento traz. Quando ele não consegue lidar com a própria condição existencial na relação com o paciente - refugia-se na técnica.

A relação terapêutica, e aqui já podemos dispensar as distinções de áreas, parte da noção de quem somos: entes cujo modo de ser está em jogo; somos abertura de possibilidades -Dasein. Uma relação entre Psicólogo e Paciente que são entes temporais em abertura, carregados de sentido.

O Psicólogo, ao tomar uma atitude anti-natural - EPOCHÉ- busca a compreensão do fenômeno, a verdade Aletheia (velamento e desvelamento) e não Veritás (representação que se sobressai sobre as demais e as encobre). Parte inicialmente do acolhimento, ou seja, estabelece um bom vínculo que possibilite a relação de escuta e fala sustentada na angústia (FEIJOO, 2000).

Como entes em abertura, nos mostramos ao modo de cuidado da pré-ocupação, que pode ser substitutiva quando o psicólogo dá tutela ao paciente, dá respostas, ou da anteposição libertadora, em que psicólogo acompanha o paciente e na hora da escolha "da um passo atrás", proporciona que o outro seja livre em suas escolhas. 


\title{
6 Considerações finais
}

Ao escolher apenas a primeira sessão de um processo que completou 35 atendimentos realizados em um hospital geral, tive a intenção de mostrar o quanto não há o que deve ser feito psicólogo, mesmo quando este se encontra inserido em uma equipe. Seja no contexto clínico em consultório particular ou em instituições de saúde, a relação terapêutica pode ser a mesma. A diferença está, certamente, na maneira como o psicólogo compreende a si e, consequentemente, ao outro e ao próprio processo de ajuda. Segundo Sá:

\begin{abstract}
A terapia não é um processo conduzido voluntariamente pelo terapeuta(...) (...) A clínica com base hermenêutica, pretende-se um espaço de tematização de sentido, de desnaturalização dos sentidos previamente dados, da ampliação dos limites dos horizontes de compreensão. O "si mesmo" é sempre o lugar provisório de uma narrativa na primeira pessoa, provisório porque a narrativa que sustenta a sua identidade está sempre fazendo, ainda que perseguíssemos a tarefa impossível de não mudar, seria necessário o esforço contínuo de repetir a mesma narrativa. Pensar o sentido da clínica é desconstruir a idéia de aplicação de uma técnica já dada, de uma psicotecnologia neutra que visa ajudar pessoas a atingirem objetivos pessoais. $O$ espaço clínico busca acolher e sustentar a vida enquanto questionamento, enquanto produção narrativa de sentido. (2002, p. 26-27)
\end{abstract}

\section{Referências}

ANGERAMI-CAMON, V. A. (Org.). Psicologia da saúde: um novo significado para a prática clínica. São Paulo: Pioneira Thomson Learning, 2006.

BRAIER, E. A. Psicoterapia breve de orientação psicanalítica. São Paulo: Martins Fontes, 1997.

CARVALHO, J. A. Faz de conta na saúde. O Globo. 11/05/09.

CURY, U. E. Plantão Psicológico em Clínica Escola In: MAHFOUD, M. (Org.). Plantão psicológico: novos horizontes. São Paulo, Editora Companhia Ilimitada, 1999.

EISENHLOHR, M. G. V. Serviço de aconselhamento psicológico do IPUSP: breve histórico de sua criação e mudanças na década de 90 . In: MORATO, $\mathrm{H}$. T. Aconselhamento psicológico centrado na pessoa: novos desafios. São Paulo. Casa do Psicólogo, 1999.

FIORINI, H. Teorias e técnicas de psicoterapias. São Paulo: Martins Fontes, 2004, edição ampliada.

FEIJOO, A. M. L. C. A escuta e a fala em psicoterapia: uma 
proposta fenomenológico-existencial. São Paulo, Vetor, 2000.

FEIJOO, A. M. L. C. A existência para além do sujeito. A crise da subjetividade moderna e suas repercussões para a possibilidade de uma clínica psicológica com fundamentos fenomenológicoexistenciais. Rio de Janeiro, Edições IFEN: Via Verita, 2011.

FORGHIERI, Y. C. Psicologia fenomenológica. São Paulo, Pioneira, 1993.

FORGHIERI, Y. C. Aconselhamento Terapêutico: origens, fundamentos e prática. São Paulo. Thomson Learning, 2007.

GIORGI, A. Phenomenology and Psychology research. Pittsburgh, Duchesse University Press, 1985.

GIORGI, A.; SOUSA, D. Método fenomenológico de investigação em psicologia. Fim de Século, Lisboa, 2010.

GORAYEB, R. Psicologia da Saúde no Brasil. Psicologia: teoria e pesquisa, Brasília, v. 26, n. especial, p. 112-122, 2010.

GUARIDO, E. L.; CAMPOS, F. C. B. Clínica ampliada é prática do psicólogo na saúde pública. Múltipla, São Paulo, v. 1, n. 1, p. 38-41, 2001.

LEMGRUBER, V. Histórico da Psicoterapia Breve. In: SEGRE, C. D. Psicoterapia breve. Lemos Editorial, São Paulo, 1997.

MINAYO, M. C. S.; CAMPOS, G. W. S.; AKERMAN, M. (Orgs.). Tratado de saúde coletiva. São Paulo/Rio de Janeiro: Editora Hucitec/Editora Fiocruz, 2006.

PAIM, J. S. Uma análise sobre o processo da reforma sanitária brasileira. Revista do Centro Brasileiro de Estudos de Saúde, Rio de Janeiro, v. 33, n. 81, jan/abr 2009.

ROSENTHAL, R. W. O Plantão de Psicólogos no Instituto Sedes Sapientes: uma proposta de atendimento à comunidade. In: MAHFOUD, M. (Org.). Plantão psicológico: novos horizontes. São Paulo, Editora Companhia Ilimitada, 1999.

SÁ, R. N. Elementos introdutórios para uma reflexão sobre a atenção nas práticas psicológicas clínicas a partir de uma atitude fenomenológica. VIII Simpósio nacional de práticas psicológicas em instituição. São Paulo: USP, 2008.

SÁ, R. N. Práticas psicológicas clínicas, verdade e liberdade: reflexões fenomenológicas. IX Simpósio nacional de práticas psicológicas em instituição. Recife: PUC, 2009.

SÁ, R. N. A Psicoterapia e a questão da técnica. Arquivos Brasileiros de Psicologia, Rio de Janeiro, v.54, n. 4, 2002.

SANTOS, N. C. A, ; SLONCZEWKI, T.; PREBIANCHI, H. B.; OLIVEIRA, A. G.; CARDOSO, C. S. Interconsulta Psicológica: demanda e assistência em hospital geral. Psicologia em Estudo, Maringá, v. 16, n. 2, Maringá, Apr./June 2011.

SEBASTIANI, R. W.; MAIA, E. M. C. Contriubuições da Psicologia da Saúde-Hospitalar na atenção ao paciente cirúrgico. Acta Cirúrgica Brasileira, São Paulo, v. 20, suppl. 1, São Paulo, 2005. 
SPINK, M. J. P. Psicologia social e Saúde: Práticas, Saberes E Sentido. $3^{a}$ ed. Petrópolis: Editora Vozes, 2003.

VALLE, E. R. M.; FRANÇOSO, L. P. C. Psicologia e Enfermagem: a questão do adoecer. Psicologia Argumento, Curitiba, v. 15, n. 20, p. 62-70, 1997.

VALLE, E. R. M. Ser - no Mundo - com - o - filho portador de câncer: Hermenêutica de discursos de pais. 1988. $123 \mathrm{f}$ Tese (Doutorado em Psicologia) - Instituto de Psicologia, Universidade de São Paulo, São Paulo.

VENDRUSCOLO, J. A criança curada de câncer: modos de existir. 1998. 189f. Dissertação (Mestrado em Psicologia) - Faculdade de Filosofia Ciências e Letras de Ribeirão Preto, Universidade de São Paulo, Ribeirão Preto.

VENDRUSCOLO, J. Visão da criança sobre a morte. Medicina, Ribeirão Preto, v. 38, n. 1, p. 26-33, 2005.

VENDRUSCOLO, J.; BARRETO, L. M.; EL KHOURI, R. N.; FERREIRA, V. L. R.; MEZZIARA, S. R. B. Aconselhamento terapêutico-uma nova possibiliadade de atendiemento psicológico a partir do plantão psicológico. In: 9 CONIC, 2008, Ribeirão Preto. 9 CONIC, 2008.

VENDRUSCOLO, J.; DEL LAMA, L. C. Estágio supervisionado de psicologia da saúde em hospital-geral: a formalização de uma prática. In: 9 CONIC, 2008, Ribeirão Preto. 9 CONIC, 2008.

VENDRUSCOLO, J.; COSENZO, T. G.; FESTUCCI, I. M. G.; SOUZA, M. J. S. Minha barriga está doendo! Um pedido de ajuda para a dor psíquica. In: 9 CONIC, 2008, Ribeirão preto. 9 CONIC, 2008.

VENDRUSCOLO, J.; COSENZO, T. G.; FESTUCCI, I. M. G.; SOUZA, M. J. S. Plantão Psicológico e Aconselhamento terapêutico na enfermaria pediátrica: iniciando uma parceira. In: 9 CONIC, 2008, Ribeirão preto. 9 CONIC, 2008.

VENDRUSCOLO, J. Atendimentos breves na área da saúde na perspectiva fenomenológico-existencial. In: IX Congresso brasileiro de psicoterapia existencial, 2009, São Paulo. IX Congresso Brasileiro de Psicoterapia Existencial.

\section{Endereço para correspondência}

Juliana Vendruscolo

Unaerp Campus Ribeirão Preto - Av. Costábile Romano, 2.201, CEP 14096-

900, Ribeirania - Ribeirão Preto, SP, Brasil

Endereço eletrônico: jvendruscolo@yahoo.com.br

Recebido em: 21/10/2011

Reformulado em: 16/09/2012

Aceito para publicação em: 11/10/2012

Acompanhamento do processo editorial: Ana Maria Lopez Calvo de Feijoo 


\section{Notas}

*Profa. Dra Juliana Vendruscolo, Docente na Universidade de Ribeirão Preto e na Universidade Paulista.

${ }^{1}$ Os atendimentos foram realizados pelos estagiários. 